\title{
Anterolateral ligamentin anterolateral rotatuar instabilitedeki rolü
}

\author{
Role of anterolateral ligament in anterolateral rotatory instability
}

\author{
Egemen Turhan ${ }^{1}$, Murat Demirel2,3 ${ }^{2}$, Gazi Huri' ${ }^{1}$ Özgür Ahmet Atay ${ }^{1}$ \\ ${ }^{1}$ Hacettepe Üniversitesi Tıp Fakültesi, Ortopedi ve Travmatoloji Anabilim Dalı, Ankara \\ ${ }^{2}$ Ankara Bayındır Hastanesi, Ortopedi ve Travmatoloji Bölümü, Ankara \\ ${ }^{3}$ Ankara Üniversitesi Tıp Fakültesi, Anatomi Anabilim Dalı, Klinik Anatomi Bilim Dalı, Ankara
}

Diz ekleminde ön çapraz bağ (ÖÇB) yırtıkları en sık görülen yaralanmalardandır ancak halen güncel cerrahi rekonstrüksiyon yöntemleri ile doğal dinamik diz fonksiyonunu elde etme ile ilgili sorunlar sıklıkla bildirilmektedir. Anatomik ÖÇB rekonstrüksiyonunun amacı dizin normal anatomi ve kinematiğini tekrar sağlamaktır. ÖÇB yaralanmalı dizlerde tam rotasyonel stabiliteyi sağlamadaki başarısızlıklar, dizin lateral bölgesindeki yapıların güçlendirilmesi amacını taşıyan eklem-dışı tenodez rekonstrüksiyonları gibi prosedürlerin, ÖÇB rekonstrüksiyonu ameliyatlarına eklenmesi gerekliliği fikrini güçlendirmiştir. Anatomik olarak, bu klinik gözlemler dizin anterolateral bölgesindeki yapıların yapısal içerik ve stabilize edici katkılarının değerlendirilmesi amaçlarını taşıyan çalışmaların yapılmasına olan ilgiyi uyarmıştır. Bunun sonucunda anterolateral ligament (ALL) gibi bir yapının yeniden keşfi olarak adlandırılabilecek ayrıntılı incelemelerini içeren araştırmalar yapılmıştır. Ayrıca, ÖÇB yırtıkları ile ALL yaralanmalarının yakın ilişkisi ve pivot kaydırma (pivot shift) testinde rezidüel anterolateral rotasyonel instabilitenin birlikteliği, ALL'nin anatomik ve yapısal özelliklerine olan ilginin artmasına da sebep olmuştur. ALL ilk kez Segond tarafından 1879 yılında, iliotibial bandın (ITB) iç rotasyon sırasında gerilmesini tanımladığı çalışmada belirtilmiştir. Bu yapıyı Segond, inci benzeri, fibröz bir bant olarak tanımlamıştır. Ama ALL anatomisine esas ilginin artmasını sağlayan çalışma Claes ve ark., tarafından yapılmış ve o dönemde bir çok yazılı ve görsel basında "Dizde yeni bir bağ bulundu." şeklinde haberler yer almıştır. Bu makalenin amacı anterolateral ligamentin klinik anatomisi, biyomekanik ve radyolojik özelliklerini ve ÖÇB yaralanmasındaki önemini gözden geçirmektir. ÖÇB rekonstrüksiyon yöntemlerinden sonra oluşan instabil durumları anlamak için daha çok bilimsel araştırmaya ihtiyaç olduğu açıktır. Daha ileri anatomik, biyomekanik ve radyolojik çalışmalar altta yatan patolojileri açıklayacaktır.

Anahtar sözcükler: anterolateral ligament; ön çapraz bağ

\begin{abstract}
Anterior cruciate ligament $(\mathrm{ACL})$ ruptures in knee-joint are one the most frequent injuries; however, it is commonly reported that there are still problems in terms of obtaining natural dynamic knee function using the current surgical reconstruction methods. The aim of anatomic ACL reconstruction is to restore normal anatomy and perfect knee kinematics. The failure in restoring full rotational stability in knees injured with ACL supports the idea that $A C L$ reconstruction surgeries necessitates the addition of the procedures such as extra-articular tenodesis reconstructions, which aim to strengthen the structures in the lateral part of the knee. Anatomically, these clinical observations arouse the interest in doing studies which aim to examine the structural content of the structures in anterolateral part of the knee and its stabilizing contributions. As a result, some research has been done, which can be called the rediscovery of the structure anterolateral ligament (ALL) including its detailed examinations. In addition, the close relationship between ACL ruptures and ALL injuries and the association of residual anterolateral rotational instability in pivot shift test have led to an increase in the interest of the anatomic and structural features of ALL. ALL was first indicated by Segond in 1879 , in his study when he described the extension of iliotibial band (ITB) during internal rotation. Segond described this structure as a pearly, fibrous band. However, the study which aroused the main interest in the anatomy of ALL was carried out by Claes et al., and there was news in written and visual media during that time stating that "a new ligament was discovered in the knee". It is clear that to understand the instability patterns after ACL reconstruction procedures, more scientific researches needed. Further anatomical, biomechanical and radiological studies will clarify the underlying pathologies. The aim of this article is to investigate the clinical anatomy of anterolateral ligament and its biomechanical and radiological features.
\end{abstract}

Key words: anterolateral ligament; anterior cruciate ligament

- Illetişim adresi: Prof. Dr. Egemen Turhan, Hacettepe Üniversitesi Tıp Fakültesi, Ortopedi ve Travmatoloji Anabilim Dalı, Ankara Tel: 0533 - 7415122 e-posta: dregementurhan@gmail.com

- Geliş tarihi: 29 Nisan $2020 \quad$ Kabul tarihi: 30 Mayıs 2020 


\section{ANTEROLATERAL LIGAMENT (ALL) VE ÖN ÇAPRAZ BAĞ YARALANMASINDAKI YERi}

Ön çapraz bağ (ÖÇB) yaralanması ortopedi ve travmatoloji pratiğinde en sık karşılaşılan yaralanmalardan biri olup sıklıkla ÖÇB rekonstrüksiyonu ile tedavisi yönetilmektedir. ${ }^{[1]}$ Her ne kadar cerrahi işlemlerin ana hedefi normal anatomi ile birlikte gerçeğe yakın bir diz kinematiği elde etmek olsa da bu işlemlerin rotasyonel stabilitenin önüne geçmek konusunda yetersizlikleri bulunduğunu bilmekteyiz. Bu rotasyonel instabilitenin önüne geçmek noktasında eklem dışı destek tedaviler tekrar gündeme gelmiş ve arayışlar bu noktada yoğunlaşmıştır. ${ }^{[2,3]}$ ÖÇB rekonstrüksiyonu sonrasında pivot kaydırma testinin halen belli ölçülerde \%30-40 olguda devam ettiği rapor edilmiştir. ${ }^{[4]}$ Önceleri bu fenomenin nedeni olarak kıkırdak ve meniskal patolojiler sorumlu tutulmuş olsa da günümüzde çoğu araştırmacı dizin lateral yapılarının önemine odaklanmıştı..$^{[5]}$ Claes ve ark. tarafından 2014 yılında sansasyonel bir çalışma ile bu yapılar tekrar popülarize edildikten sonra anterolateral ligament (ALL) hakkında sayısız çalışma literatürde yer bulmuştur. ${ }^{[6]}$

ilk olarak Paul Segond tarafindan 1879 yılında 'Inci Bağı' adı altında fibröz direnç bağı olarak tanımlanan bu yapı çeşitli makalelerde başka isimler altında da ele alınmıştır. ${ }^{[7]}$ Segond ayrıca dizin rotasyonel yaralanması sonrasında tibianın proksimal anterolateral bölgesinde oluşan kopma kırığının ÖÇB yaralanması için patognomonik bir bulgu olduğunu da üzerine basarak belirtmiştir. ${ }^{[7,8]}$ Yüz yıllık bir sessizliğin ardından Hughston ve ark. 1976 yılında, Müller ve ark. 1982 yılında, Terry ve ark. 1993 yılında, Campos ve ark. 2001 yılında, Vieria ve ark. 2007 yılında, Vincent ve ark. ise 2012 yılında bu anatomik yapının önemine değinen yazılarını literatüre sunmuştur. ${ }^{[9-13]}$ Ayrıca farklı yazarlar bu anatomik yapıyı lateral kapsüler ligament, anterior oblik bant, orta lateral kapsüler ligament, orta üçüncü lateral kapsüler ligament ve retrograd yol lifleri gibi çeşitli terimlerle adlandırdı. ${ }^{[9-13]}$ Aynı yapı için farklı isimler kullanılması da bu bağın doğasını anlamak için karışıklıklara yol açmıştır.

En son olarak, Vieria anterolateral bağ terimini kullanan ilk araştırmacı oldu. ${ }^{[12]} \mathrm{Her}$ ne kadar Claes ve ark.'nın ALL ile ilgili anatomik çalışması, konuyla ilgili yeni bir buluş olmamasına rağmen, bu grubun güçlü sosyal medya ağı nedeniyle, "dizde keşfedilen yeni bir bağ” olarak popüler hale getirildi.

\section{Anterolateral Yapılar ve Pivot Kaydırma Fenomeni}

Tibianın iç rotasyonuna karşı koyan ana yapılar, iliotibial bandın (ITB) yüzeyel, derin ve kapsülo-osseöz tabakası, anterolateral ligament, orta 1/3 lateral kapsül ve lateral menisküsün arka köküdür. ${ }^{[14]}$ Biyomekanik çalışmalara göre, iTB'nin her üç tabakası da dizin iç rotasyonunu sınırlayan birincil anatomik dizgindir. ${ }^{[1]}$ Klinik olarak, ön çapraz bağ yokluğunda dizin aşırı iç rotasyonu, Galway ve ark. tarafindan ilk kez 1972'de tarif edilen pivot kaydırma testi ile değerlendirilebilir. ${ }^{[15]}$ Bu test; dizin ekstansiyonda femoral kondil üzerinde lateral tibial platonun öne subluksasyonu ve fleksiyona getirilmesi ile spontan redüksiyonu olarak tanımlanır. Güncel bilgi olarak, pivot kaydırma testi ÖÇB yaralanmasının tanısı için en değerli klinik testtir ve ayrıca patognomonik olarak kabul edilmektedir. Ne yazık ki, birçok ortopedi ve travmatoloji uzmanı hastalarının ÖÇB rekonstrüksiyonundan sonraki takiplerinde farkI derecelerde pivot kaydırma testinin devam ettiğini gözlemlemektedir. ${ }^{[16]}$

Bu rezidüel pivot kaydırma fenomeni; bazı yazarlar tarafından, dizin ÖÇB ile beraber yaralanan ikincil stabilizatörlerinin teşhisinde veya tedavisinde yetersizliğe bağlanmış ise de (örn. lateral menisküs posterior kök yırtılması, menisektomi), birçok cerrah bu fenomeni izole ÖÇB hasarlı hastalarda da ÖÇB rekonstrüksiyonu sonrası rapor etmiştir. ${ }^{[16]}$

Pivot kaydırma testi ile ilgili biyomekanik çalışmalar, sublukse olmuş dizde birincil redükte eden yapının iTB'ye ait olduğunu ortaya koymuştur. ${ }^{[16]}$ Gerçekte, ÖÇB yaralanması olan hastaların hiçbirine ITB yaralanması eşlik etmemektedir. ${ }^{[16]}$

Bu klinik gerçeklik, araştırmacıların dizin anterolateral kompleksi hakkında daha fazla çalışmaya odaklanmasına sebep olmuştur.

\section{Anterolateral Ligament Hakkında Ne Biliyoruz?}

Farklı yazarlar tarafindan ALL'nin varlığı ve yapısı hakkında çok sayıda anatomik çalışma olmasına rağmen, Claes ve ark. ALL'nin anatomik özelliklerini kapsamlı olarak tanımladı..6,8-13] Claes ayrıca ALL ve Segond kırığı arasındaki ilişkiyi de net bir şekilde ortaya koymuştur. ${ }^{[6]}$ Kadavralarda ALL'yi doğru olarak tanımlamak için Daggett tarafından tarif edilen teknik kullanılabilir. ${ }^{[17]}$ ALL dizin anterolateral bölgesinde üçüncü tabakada, eklem kapsülü üzerinde uzanır. Daggett'in tekniğini kullanarak ALL'yi tanımlamak için, ilk olarak ITB'nin Gerdy tüberkülüne kadar olan kısmının uzaklaştırılması gerekmektedir. Diseksiyon sırasında tibianın iç rotasyonu ALL'nin düzgün görüntülenmesi için önemli bir ayrıntı olarak tavsiye edilir. Biseps femorisi kaldırıldıktan sonra ITB, lateral kollateral ligament ( $L C L)$, kapsül ve biceps femoris gibi bitişik dokulardan ALL'nin tanımlanması için titiz bir diseksiyon yapılmalıdır. ${ }^{[17]}$ 


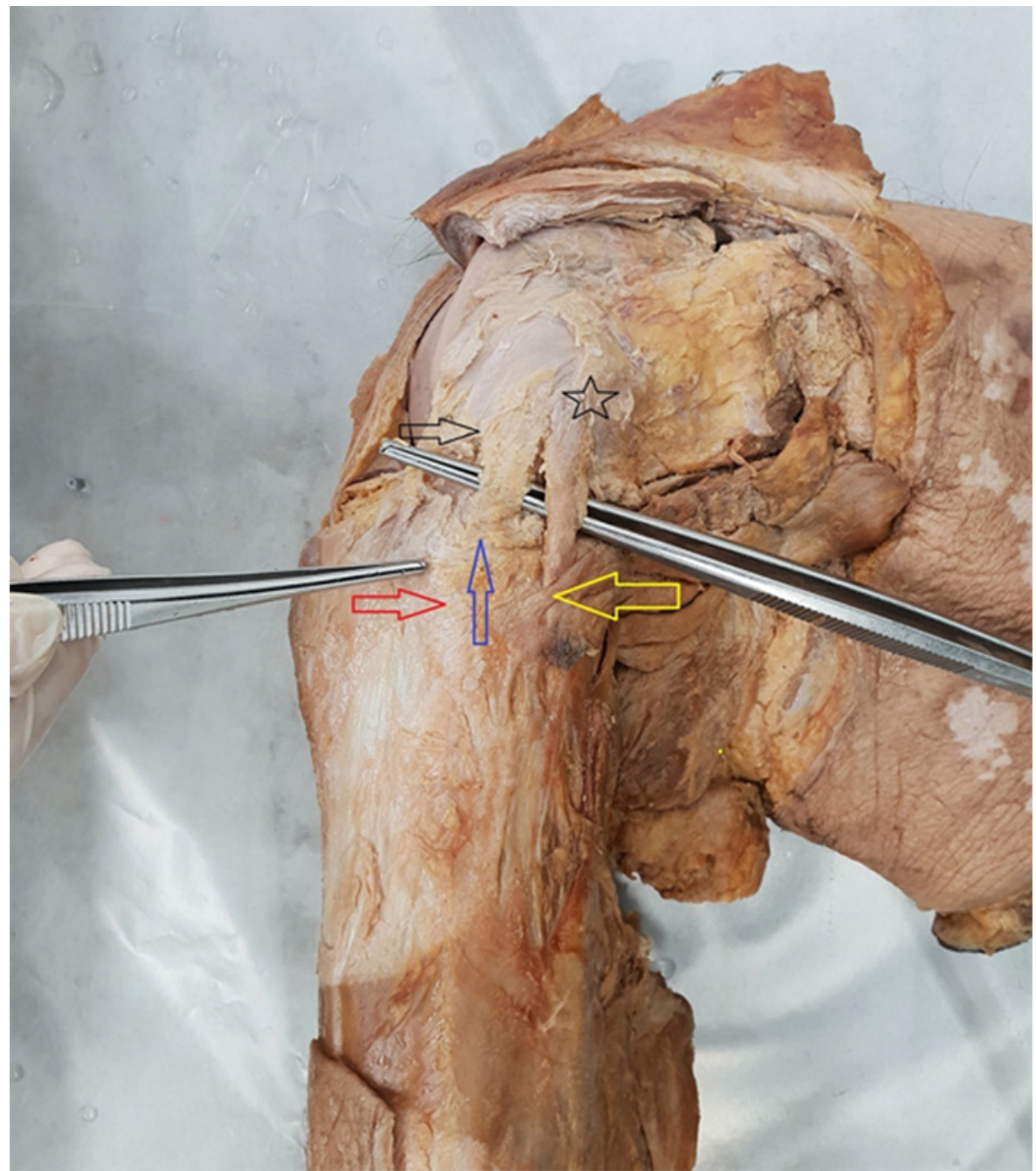

Şekil 1. ALL, lateral kollateral bağın (LKB) önünde distale doğru uzanır. (siyah yıldız, LKB'nin femoral orijini; siyah ok, ALL'nin femoral orijini; kırmızı ok, Gerdy tüberkülü; mavi ok, ALL'nin tibial yerleşimi; sarı ok, fibula başı).

\section{Anterolateral Ligamentin Morfometrisi}

Kadavra çalışmalarının analizine göre, ALL'nin femoral tutunma yerini genellikle lateral epikondilin posterior ve proksimalinde olduğu gösterilmiştir. Ağırlıklı olarak LCL'nin önünde seyretmektedir, ancak bazı makalelerde LCL'nin posteriorunda da uzanımı olduğundan bahsedilmiştir. ${ }^{[6,9-15]}$ ALL'nin femoral orijini doğrudan kemiğe yapışır ve ortalama çapı 11,85 mm'dir. ALL; diz nötral pozisyonda iken LCL'ye neredeyse paralel ilerler.

ALL'nin bazı liflerinin eklem çizgisi hizasında, lateral menisküse ve kapsüle bağlandığı da gösterilmiştir. ALL'nin distal yerleşimi femoral orijinden daha sabittir. ${ }^{[6]}$ ALL'nin tibial yapışma yeri, $11 \mathrm{~mm}$ geniş̧liğinde, Gerdy tüberkülünün yaklaşı $21 \mathrm{~mm}$ posteriorunda ve eklem hattının 4-10 mm altında proksimal tibiada bulunur (Şekil 1). ALL'nin uzunluğu (34-59 mm) ve kalınlığı (erkek: 2 mm, kadın: $1 \mathrm{~mm}$ ) cinsiyete göre değişir. Ayrıca tibial bağlantının Gerdy'nin tüberkülü ile fibula başı arasında olduğu kabul edilir. ${ }^{[1,6,18]}$

\section{Anterolateral Ligamentin Radyolojik Anatomisi}

ALL rekonstrüksiyonunun popülaritesi arttıkça, radyolojik belirteçlerin önemi de ayrı bir ilgi alanı haline gelmiştir. Minimal invaziv prosedürler için, bu yer işaretlerinin bilgisi greft pozisyonu için gereklidir. Ameliyat sırasında, bu yer işaretlerinin floroskopik görüntüleri, uygun tünel konumlandırması için çok önemlidir. Literatürde ALL'nin radyografik izlerinin analizi için tasarlanmış dört iyi çalışma vardır. ${ }^{[19-22]}$ Yukarıda belirtildiği gibi, ALL'nin femoral orijininin radyolojik 
izdüşümleri anatomik yeri gibi değişkenlik gösterir. Lateral görünümde Helito ve ark., Blumensaat çizgisini referans noktası olarak önermiştir. Radyolojik çalışmasına göre, femoral bağlanma yeri Blumensaat çizgisi boyunca femoral kondilin ön kenarından yaklaşık yarı yoldadır. ${ }^{[19]}$

Kennedy ve ark. femoral kadran sistemi kullanmıştır ve ALL'nin femoral orijininin femoral posterior korteksi ile Blumensaat çizgisinin kesişme noktası olduğunu bulmuştur. Femoral bağlanma yerini postero-inferior kadranda, $8,4 \mathrm{~mm}$ proksimalde ve lateral epikondil merkezinin posteriorunda tanımlamışlardır. ${ }^{[20]}$ Rezansoff ve ark. ALL orijinini Blumensaat çizgisi ile Blumensaat çizgisine paralel posterior kondiller eklem kenarından alınan bir posterior femoral kortikal çizgi boyunca tanımlamışlardır. ${ }^{[21]}$ Heckmann ve ark. ALL orijini Blumensaat çizgisi boyunca ölçülen femoral kondilin arka kenarından yaklaşık \%37'lik bir mesafede konumlandırmıştır. ${ }^{[22]} A L L$ Expert Group'a göre, Kennedy yöntemi diğerlerinden ziyade tercih edilmektedir. ${ }^{[18]}$

Tibial yapışma yeri için, lateral görünümde Kennedy ve Helito, tibial plato merkezinin ${ }^{[19-20]}$ posteriorunu önermiştir. Rezansoff'a göre, tibial nokta merkezin daha posteriorunda yer almaktadır. ${ }^{[21]}$ Diğer yazarların aksine, Heckmann plato merkezinin anteriorunu önermiştir. ${ }^{[22]} A L L$ Expert Group'un görüşüne göre, tibial yapışma yeri lateral görünümde proksimal tibial plato merkezine yakın ve ön arka görünümde tibial eklem hattının yaklaşık $7 \mathrm{~mm}$ altında olmalıdır. ${ }^{[18]}$

\section{Anterolateral Ligamentin Biyomekaniği}

ALL ile ilgili biyomekanik çalışmalar bu bağın doğal ve rekonstrükte edilmiş halinin kinematiği üzerine odaklanmıştır. Claes ve ark.'na göre kadavra modellerinde hem ALL hem de ÖÇB'nin çift demeti deneysel olarak kesildiğinde daha ileri pivot kayması elde edilebilmektedir. ${ }^{[6]}$ ITB'nin redükte edici etkisinden optimal faydalanabilmek için tüm vücut kullanılmayan kadavra modelleri genellikle bir yazılım doğrultusunda biyomekanik sonuçları vermektedir ve ne yazık ki hata payı büyüktür. Tüm vücut kadavralarda izole ALL veya ÖÇB'nin bir demet (anteromedial veya posterolateral) eksikliği 1 . derece pivot kaymasına neden olurken, ÖÇB'nin tamamı ve ALL'nin kombine rüptürleri 3. derece pivot kaymasına neden olabilmektedir. ${ }^{[23,24]}$

ALL biyomekaniği ile ilgili son çalışmalardan sonra, dizin rotasyonel stabilitesindeki rolü ayrıntılı olarak tanımlanmıştır. Farklı kadavra modellerinde çekme mukavemeti testi ( $20 \mathrm{~mm} /$ dakika) ile nihai yük değeri ortalama 189 Newton ve sertliği $31 \mathrm{~N} / \mathrm{mm}$ olarak gösterilmiştir. Bu test verileri ALL rekonstrüksiyonu için uygun greft seçimi açısından klinik olarak önemlidir. ${ }^{[18]}$ Aksi takdirde, güçlü ve kalın greftlerin seçimi dizin lateral kompartmanında aşırı kompresyona neden olabilir ve bu da erken lateral kompartman artritine neden olabilir.

Dizin in-vitro robotik değerlendirmeleri; ÖÇB'nin işlevsiz hale getirilmesi durumunda ALL'nin önemli bir lateral rotatuar stabilizör olduğunu ortaya koymuştur. ${ }^{[24]}$ Spesifik olarak ALL'nin, iç rotasyon torku ve ÖÇB eksikliği durumunda simüle edilmiş pivot kaydırma testi sırasında ikincil bir stabilizatör görevi gördügü gösterilmiştir. ${ }^{[25]}$

Oshima ve ark., ALL rekonstrüksiyonunun diz laksitesini azalttığını göstermiştir. Bu çalışmanın bir diğer önemli bir bulgusu ise, simüle edilmiş bir pivot kaydırma testi sırasında, ÖÇB rekonstrüksiyonu ile birlikte ALL rekonstrüksiyonu uygulaması dizin $30^{\circ}, 45^{\circ}$ ve $60^{\circ}$ fleksiyonunda iç rotasyonu azaltmasıydı. Bu bulgunun ayrıca, ALL yetersizliği bulunan dizlerde ÖÇB rekonstrüksiyonu ile karşılaştırıldığında istatistiksel olarak anlamlı gözükmesi de göz önünde bulundurulması gereken bir durumdur. ALL izometrisi değerlendirildiğinde ALL'nin $20^{\circ}$ ekstansiyonda ve iç rotasyonda sıkı, $120^{\circ}$ 'de fleksiyonda gevşek olduğu görülmüştür. Femoral yapışma yeri lateral epikondilin proksimal ve posterioru referans alındığında dizin iç rotasyonunu $90^{\circ}$ femoral pozisyonda arka tarafta femoral orijin tercih edildiğinde $90^{\circ}$ 'de iç rotasyonda olduğu bulunmuştur. Bu biyomekanik çalışmaların klinik yansımaları femoral yerleşimin ve ideal greftin uygun seçimi için önemlidir. ${ }^{[26]}$

\section{Anterolateral Ligamentin Görüntülenmesi}

Steven Claes'in popüler anatomik çalışmasından sonra, birçok radyolog ALL'nin farklı görüntüleme yöntemleriyle gösterilmesine odaklandı. ilk olarak, Segond kırı̆̆ının radyolojik açıdan ALL ile ilişkisi iyi tanımlanmıştır. Güncel bilgi olarak, Segond kırığının temeli ALL'nin kopma kırı̆̆ıdır ve dizin iç rotasyonunun ve olası varus stresinin sonucudur. Bu kırık, direkt ön-arka (AP) grafide tibianın anterolateral eklem çizgisi altında görülebilmektedir. ${ }^{[6]}$ Lateral grafilerde, ÖÇB yaralanması sonrası görülen derin lateral femoral çentik işareti de ALL hasarının dolaylı bir patolojik bulgusu olduğu öngörülmektedir. (Şekil 2)

ALL; koronal manyetik rezonans (MR) görüntüleme taramalarında T2 ağırlıklı ve proton yoğunluklu yağ baskılanmış değerlendirme ile görüntülenebilir. MR bulgularına göre ALL, lateral menisküs ile ilişkisi göz önünde bulundurularak; femoral, meniskal ve tibial olmak üzere üç kısma ayrılmıştır. ALL'nin femoral parçası 

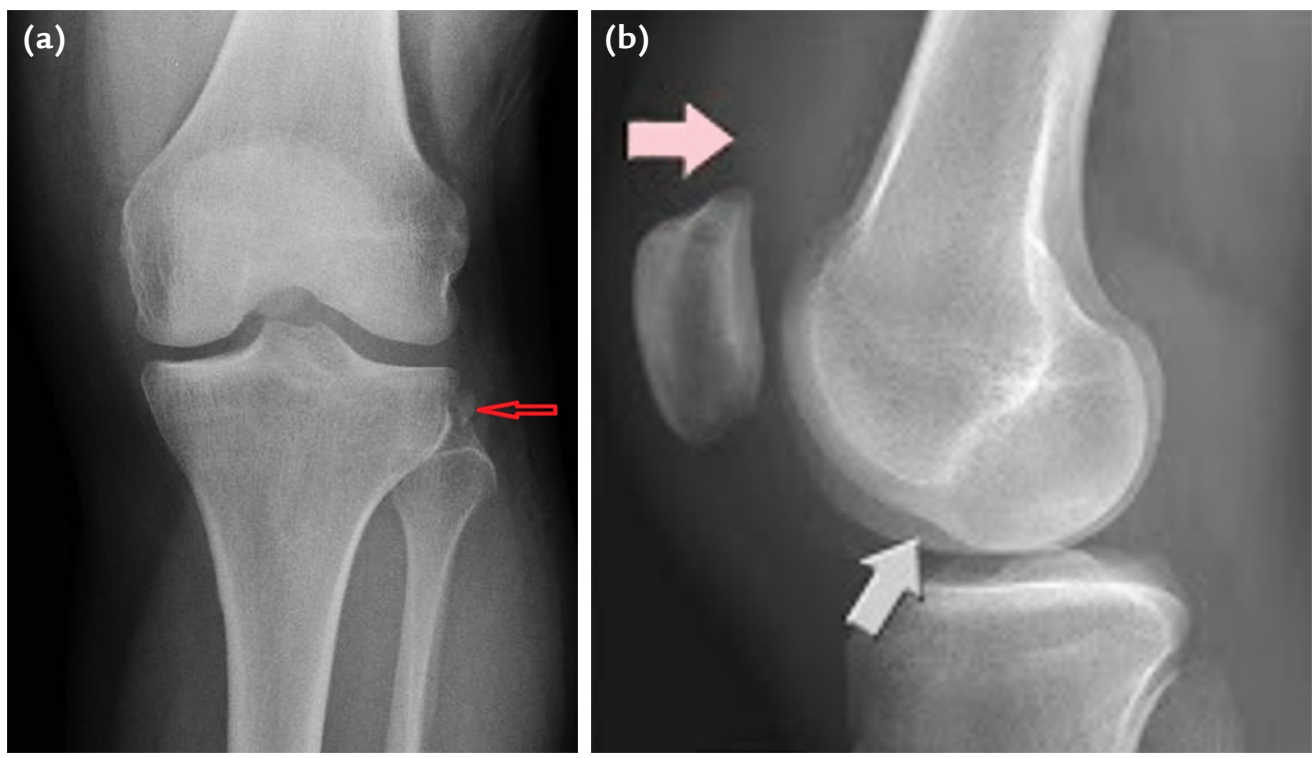

Şekil 2. a, b. Segond kırığı, proksimal tibianın anterolateralinde yer alan avulsiyon kırığıdır ve ÖÇB yaralanması için patognomoniktir. Ön arka diz grafisi ÖÇB yaralanmasına eşlik eden bir Segond kırığının tipik bir örneği (kırmızı $o k, a)$; derin lateral femoral çentik rotasyonel yaralanmaya ALL yaralanmasının eşlik edebileceğini gösteren dolaylı bir radyolojik bulgu (beyaz ok, b).
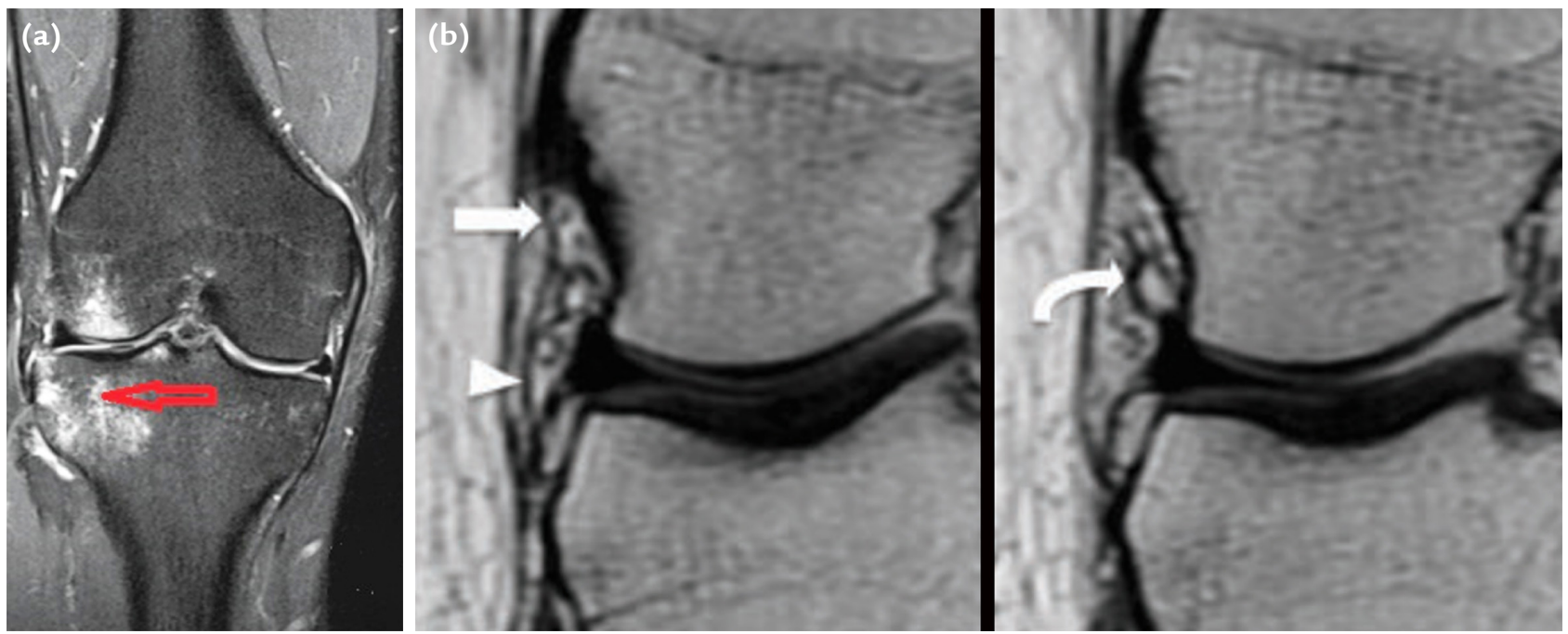

Şekil 3. a, b. Tibianın proksimal anterolateralinde bulunan kemik ödemi Segond kırı̆̆ı (kırmızı ok, a) (T2 yağ baskılı PDW koronal görüntü); ALL'nin manyetik rezonans (MR) görüntülenme ile değerlendirilmesi (beyaz oklar, b) (T1 ağrlıklı koronal MR kesitleri).

popliteus tendonunun eklem içi kısmı ile yakın bir ilişkisi vardır ve MR kesitlerinde hemen üzerinde görülmektedir. Tibial kısım inferior lateral genikülat arterlerin hemen üzerindedir. MR çalışmaları, ALL anormalliklerinin sıklıkla bağın tibial kısmında yer aldığını belgelemiştir. [27] MR'de ALL yaralanmalarının önemli bir göstergesi, lateral femoral kondilde ve arka tibial platoda bilateral olarak görülebilen rotasyonel travma sonucu oluşan kemik iliği ödeminin varlığıdır (Şekil 3). ${ }^{[28,29]}$

Son olarak, tecrübeli ellerde ultrasonografi (US) ALL yaralanmalarını doğrudan teşhis etmek için yararlı bir araç olarak görülmektedir. ALL'nin distal tibial kısmı, meniskal ve femoral kısmına göre daha net bir şekilde görüntülenebilmektedir. Anormal eko bulguları olarak ligamentin devamsızlığı ve düzensizliği US ile gösterilebilmektedir. US'nin avantajı olarak; hızlı, taşınabilir, ucuz ve hasta başında kolaylıkla yapılabiliyor olması sayılabilir. Radyolojik bulgular ancak klinik bulgularla birlikte ALL hasarının doğru tanısı için anlam kazanmaktadır. ${ }^{[26]}$

\section{ALL Rekonstrüksiyonu İçin Endikasyonlar}

ÖÇB rekonstrüksiyonu sonrası devam eden (persistant) rotasyonel instabilite tekrar yaralanmalar için önemli bir nedendir. ${ }^{[10,18]}$ Bazı hasta grupları bu rezidüel instabilite varlığında daha da risk 


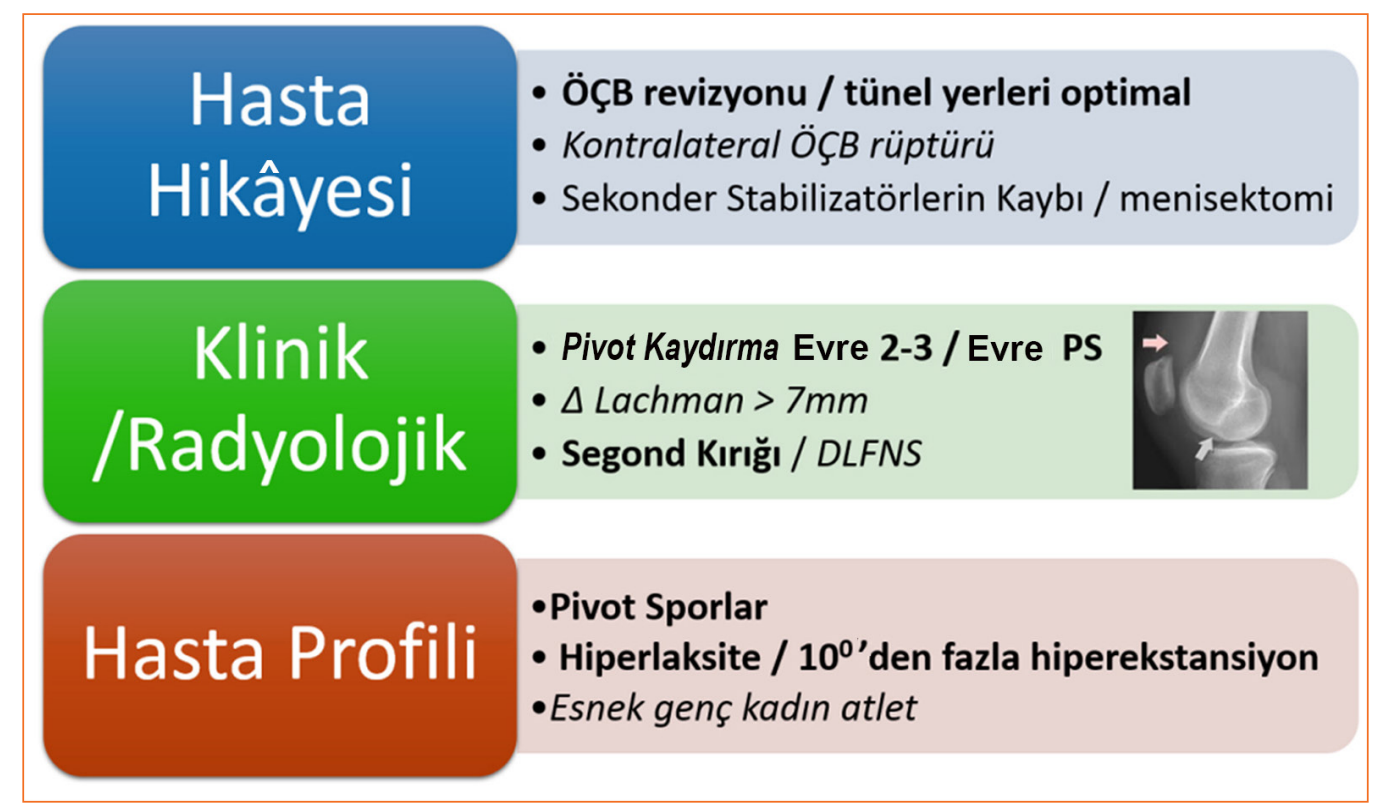

Şekil 4. ALL rekonstrüksiyonu için endikasyonların özeti (DLFNS, derin lateral femoral çentik bulgusu; PS, pivot shift).

altındadırlar. Ayrıca bu ayrıcalıklı hasta grubunun karşı dizinde de yaralanma riskinin arttığını bilmekteyiz. ALL rekonstrüksiyonu için uygun adaylara hasta hikâyesi, instabiliteye özgü muayene bulguları ile daha önce geçirdiği ameliyatlar, uğraştı̆̆ı spora özel fiziksel aktivite ve radyolojik bulgular göz önüne alarak karar vermek gerekir. Aşırı eklem esnekliği ÖÇB tamiri sonrası tekrar yaralanma için bir risk oluşturmaktadır. ALL rekonstrüksiyonu ile bu laksite sınırlandırılabilmektedir. Bu risk grubu hastalar ağırlıklı olarak genç kadın atletler ve çocuk hastalar olarak karşımıza çıkmaktadır. Hasta hikâyesinde pivot ve temas sporlarının olması, geçmiş ameliyatlarında menisektomi gibi sekonder stabilizatörlerin kaybının olması ve karşı dizde de ÖÇB rekonstrüksiyonu olması da endikasyonlar arasında sayılmaktadır. Muayene bulgusu olarak hastanın 2.-3. derece pivot kaymasının olması ve Lachman testinin $7 \mathrm{~mm}$ üzerinde olması ve ÖÇB rekonstrüksiyonu tamamlandıktan sonra rezidü pivot kaymasının ameliyat sırasında görülmesi risk grubunda kabul edilmektedir. Ayrıca muayene bulgusu olarak dizinde hiperekstansiyonu olan ve diğer eklemlerde de aşırı esnekliği bulunan hastalar ALL rekonstrüksiyonu için uygun hastalardır. Özel bir hasta grubu da revizyon hastalarıdır. Optimal tünel yerleri tercih edilmesine rağmen majör bir travma olmaksızın tekrar yaralanan hastalar için ALL rekonstrüksiyonunun revizyon cerrahisine eklenmesi kuvvetli bir öneridir. Radyolojik olarak Segond kırığı olan derin lateral femoral çentik bulgusu (DLFNS) olan hastalar için de ALL rekonstrüksiyonu önerilmektedir Bu kriterler Şekil 4'te özetlenmiştir. ALL Çalışma Grubuna göre ÖÇB revizyonu olguları, pivot sporlar, hiperlaksite, Evre 3 pivot kaydırma testi ve Segond kırığının varlığı karar kriteri olarak yer alırken Lachman testinin $7 \mathrm{~mm}$ üzeri olması, 25 yaşından genç olmak, DLFNS ve karşı dizde ÖÇB rekonstrüksiyonu öyküsü olması ikincil karar kriteri olarak önerilmektedir. ${ }^{[18]}$

\section{CERRAHI TEKNIK}

ALL rekontrüksiyonu ÖÇB rekontrüksiyonu işlemi tamamlandıktan sonra yapılmalıdır. ÖÇB için açılan tüneller ile ALL için hazırlanacak tünellerin kesişmemesi cerrahi bir püf noktadır. Birçok cerrahi yöntem tarif edilmiştir. Bu derlemede yazarların tercih ettiği minimal invaziv yöntem anlatılacaktır. Bunun dışında Sonnory-Cottet'nin Delta konfigurasyonu ve Zafagninni'nin dıştan içeriye teknikleri de popüler diğer tekniklerdir. ${ }^{[18]}$ Tercih ettiğimiz cerrahi tekniğin aşamaları Şekil 5'te gösterilmiştir.

\section{Greft Hazırlanması (Şekil 5a)}

ALL rekonstrüksiyonu için ideal greft, doğal bağın biyomekanik özellikleri göz önünde bulundurulursa grasilis tendon otogreftidir. Ancak bu tendon ÖÇB rekonstrüksiyonu sırasında kullanılmış ise perkütan iliotibial bandtan $1 \mathrm{~cm}$ eninde ve $10 \mathrm{~cm}$ boyunda bir 

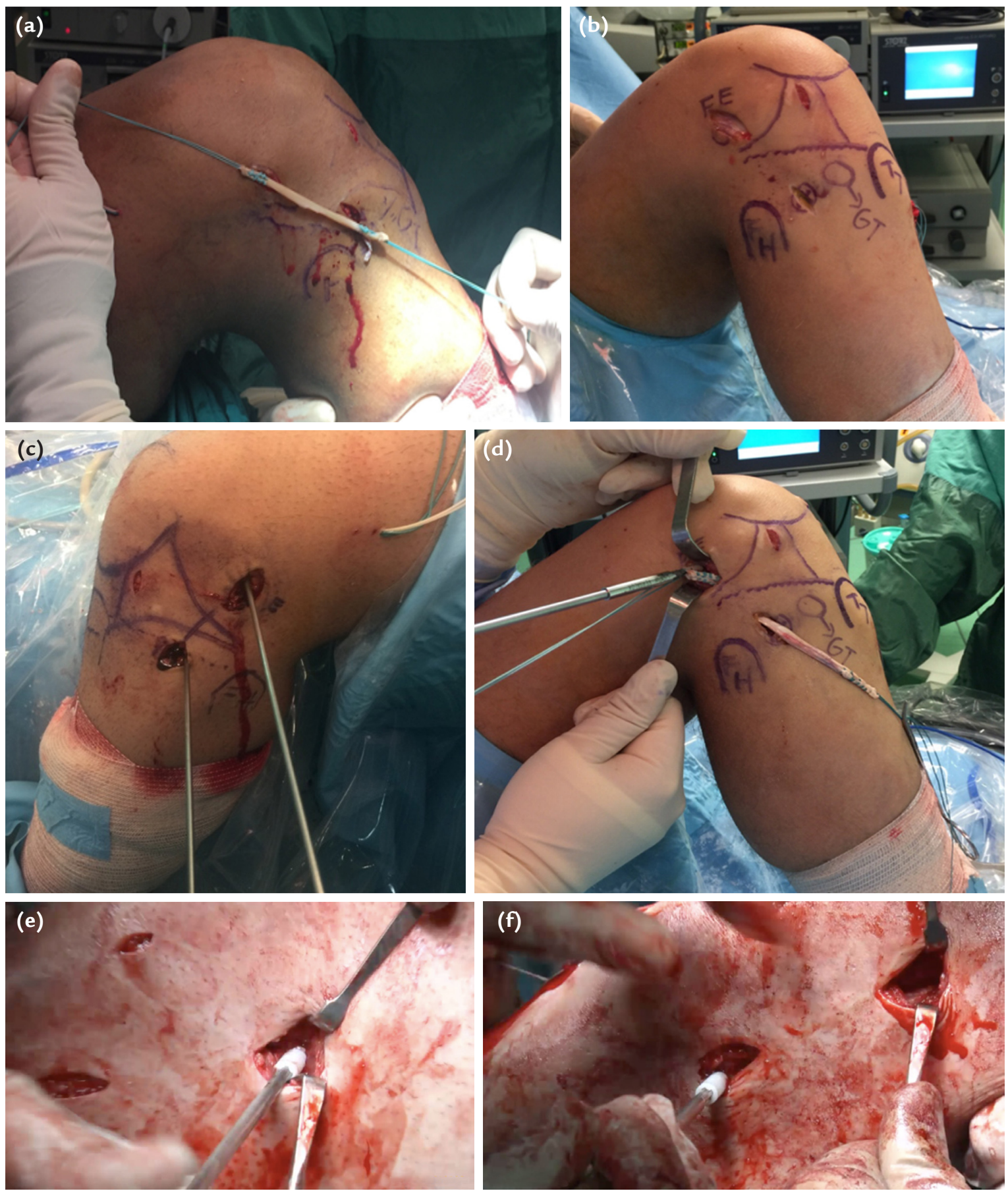

Şekil 5. a-f. ALL rekonstrüksiyonunun cerrahi basamakları: Hamstring tendonundan ALL izdüşümü ile uyumlu uzunlukta 4-5 mm çapında greftin hazırlanması (a). Lateral femoral epikondil (LFE) ve tibia proksimalinde Gerdy tüberkülü ile fibula arasında yer alan 15 mm'lik cilt kesileri (b). Femoral tünel için ideal giriş noktası LFE'nin $1 \mathrm{~cm}$ proksimal ve posteriorudur; kılavuz teli yaklaşık $30^{\circ}$ anterior ve kraniale yönlenecek şekilde ilerletilir ve kılavuz telinin üzerinden $5 \mathrm{~mm}$ çapında $2 \mathrm{~cm}$ 'lik kör bir tünel hazırlanır. Tibianın anterolateralinde eklem çizgisinin yaklaşık 7-10 mm altında Gerdy tüberkülü ve fibula başı arasında orta noktadan kılavuz teli $30^{\circ}$ distal ve anteriora yönlenecek şekilde ilerletilir; bu kılavuz telinin üzerinden $5 \mathrm{~mm}$ çapında $3 \mathrm{~cm}$ 'lik kör bir tünel hazırlanır ve her iki kılavuz teline taşıyıcı iplikler yüklenerek bacağın medialinden çıkarılır (c). Hazırlanan greft bir taşıyıcı iplik yardımı ile íTB'nin altından eklem kapsülünün üzerinde kalacak şekilde iki cilt insizyonu arasında taşınır (d). Femoral tünele yerleştirilen greft dizin pozisyonundan bağımsız olarak gerilir ve $5 \mathrm{~mm}$ çapında biyobozunur vida ile tespit edilir (e). Greft tibial tünele yerleştirilmeden önce mutlaka izometri testi yapılmalıdır. Tibial tünele greft yerleştirildikten sonra diz tam ekstansiyonda nötral rotasyon ve pozisyonda iken, greft aşırı gerilmeden $5 \mathrm{~mm}$ çapında biyobozunur vida ile tespit edilir (f). 

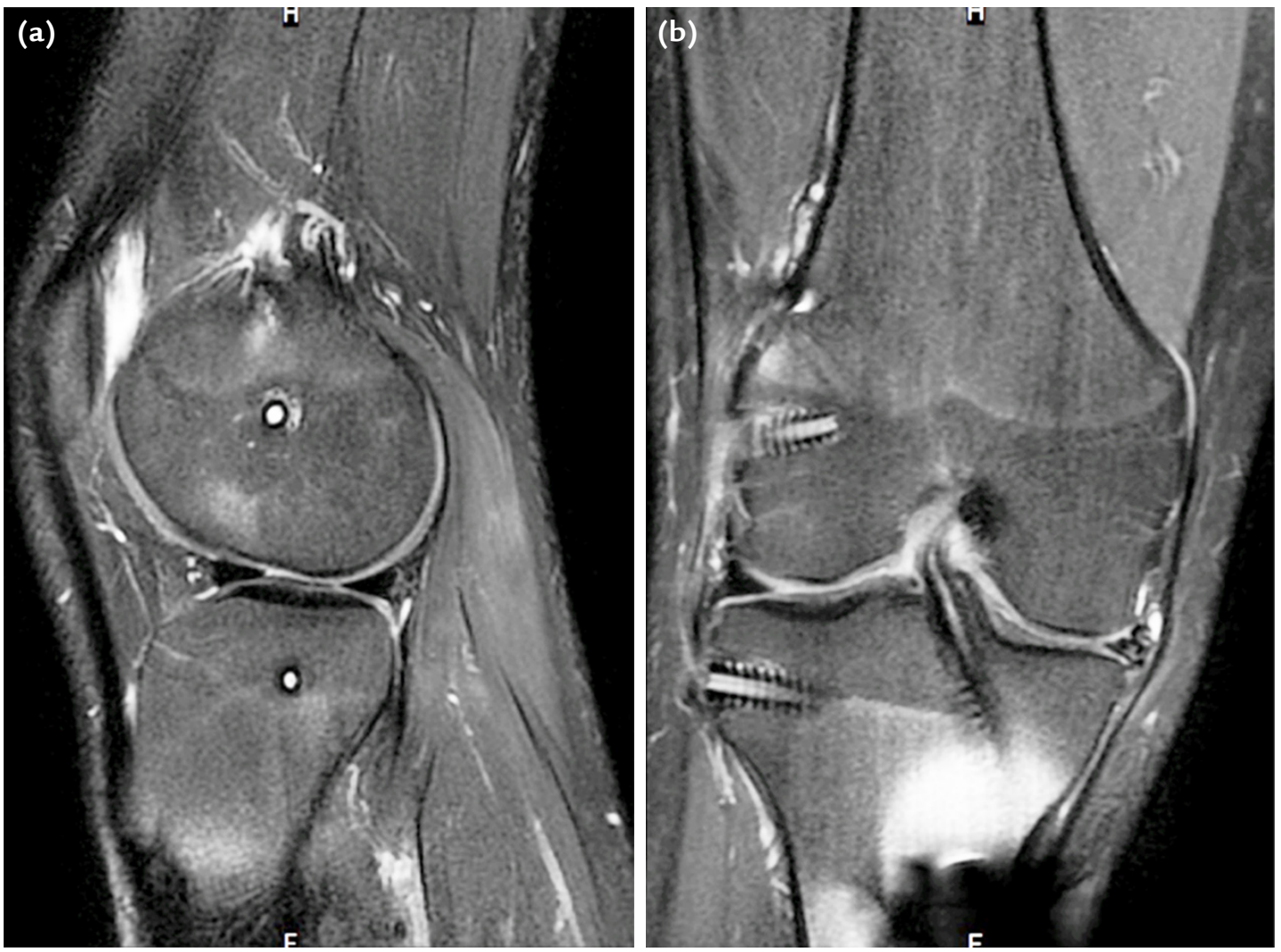

Şekil 6. a, b. ALL için hazırlanan tünellerin kontrol MR görüntüleri: Sagittal kesitte femoral ve tibial tünelin yerleşim yerleri (a). Koronal kesitlerde ÖÇB ve ALL rekonstrüksiyonu için hazırlanan femoral ve tibial tünellerin yönelimi sonucu kesişmediği gözükmektedir (b) (T2 yağ baskılı kesitler).

strip de alınabilir. Greft boyutu için hastanın dizinin boyutuna göre $8-12 \mathrm{~cm}$ 'lik ve $5 \mathrm{~mm}$ çapında bir greft yeterlidir. Kalın bir greft tercih edilmemesine özen gösterilmelidir.

Greftin her iki ucu 2,0 güçlendirilmiş kilitli dikişlerle hazırlanmalıdır.

\section{Femoral Tünelin Hazırlanması (Şekil 5b ve 5c)}

Diz $90^{\circ}$ fleksiyona getirildiğinde lateral epikondil palpe edilir ve proksimalinde $2 \mathrm{~cm}$ 'lik bir kesi yapılır. Cilt, cilt altı dokular geçildikten sonra iTB'nin liflerine paralel bir kesi ardından lateral epikondil palpe edilmeli ve bunun yaklaşık $1 \mathrm{~cm}$ proksimal ve $5 \mathrm{~mm}$ posterioru tünel için referans olarak işaretlenir. Bir kılavuz teli $(2,4 \mathrm{~mm})$ bu referans noktasından dize $30^{\circ}$ kraniale ve anteriora yönlendirilecek şekilde dizin medialinden çıkana kadar ilerletilir. Bu yönelim ile anatomik hazırlanmış ÖÇB femoral tüneli ile ALL tünelinin kesişme ihtimali indirgenmiş olur (Şekil 6). Ayrıca medialden çıkan telin damar sinir hasarı oluşturması ihtimali de anteriora yönelim sayesinde engellenmiş olur. Kılavuz telinin üzerinden $5 \mathrm{~mm}$ çapında $2 \mathrm{~cm}$ uzunluğunda kör bir tünel hazırlanır. Bu işlemin ardından telin oluğuna taşıcı sütür yüklenir ve tel medialden dışarı çıkarılır.

\section{Tibial Tünelin Hazırlanması (Şekil 5c)}

Eklem çizgisinin 7-10 mm altında Gerdy tüberkülü ve fibula başı arasında tam orta noktaya $2 \mathrm{~cm}$ 'lik bir cilt kesisi hazırlanır. Bu bölgede cilt altı dokular geçildikten sonra kemiğe kolaylıkla ulaşılır. Buradaki tünel de $30^{\circ}$ distal ve anteriora doğru yönlenecek şekilde hazırlanır; 30 mm'lik bir kör tünel greft gerimi için pay bırakması açısından yeterlidir. Tünel yerlerinden emin olmak için skopi kullanılması önerilmektedir. Bu aşamada izometri testi yapılmalıdır. Femoral ve tibial kılavuz tellerinin kemiğe mümkün olan en yakın yerine iplik sarılarak yerleştirilir ve bu ipliğin ektansiyon ile gerilmesi ve fleksiyon ile gevşemesi gözlemlenir. Eğer ekstansiyonda ipin gergin olmadığı görülüyorsa femoral tünel distal ve öne açılmış demektir ve pozisyonu yanlıştır. 


\section{Greftin Geçirilmesi ve Fiksasyonu (Şekil $5 \mathrm{~d}-\mathrm{f}$ )}

Femoral ve tibial hazırlanan cilt kesisinden künt bir diseksiyon ile iTB'nin altında eklem kapsülünün üzerinden greftin geçeceği bir pasaj hazırlanır. Greft bir taşıyıcı sütür sayesinde ITB altına yerleştirilir ve önce biyoemilir bir $5 \mathrm{~mm}$ çapında vida ile femoral tespit edilir. Bundan sonra diz tam ekstansiyon ve nötral rotasyonda iken tibial tünelde greft hafif gerilerek aynı özellikte bir vida ile tespit edilir. Greft tansiyonu aşırı olmamalıdır aksi takdirde lateral kompartman basıncında artış olması ile sonuçlanabilir. Son olarak dize ardışık hareket yapılarak greftin tansiyonu kontrol edilir.

Ameliyat sonrası rehabilitasyon programının ÖÇB rekonstrüksiyonu rehabilitasyonundan herhangi bir farklı özelliği bulunmayıp fizik tedavi aşamaları buna göre belirlenmelidir.

\section{KLINIK SONUÇLAR}

ÖÇB rekonstrüksiyonu ile beraber ALL rekonstrüksiyonuna ait çalışmaların ne yazık ki çok az bir kısmı prospektif kontrollü randomize kanıt düzeyi yüksek çaIışmalardır. ${ }^{[18]}$ Literatürdeki çoğu çalışma retrospektif olgu serisi şeklinde karşımıza çıkmaktadır. Ancak elimizde düzgün kriterleri göz önünde bulunduran literatür derlemeleri mevcuttur ve sonuçlara bakıldığı zaman ALL rekonstrüksiyonunun yüz güldürücü sonuçları olduğunu sıkça görmekteyiz. Sonuçları değerlendirirken bu ameliyatın ek morbiditesi, komplikasyonları, spora dönüş başarısı, pivot kaydırma fenomeninde azalma, ÖÇB revizyonunda azalma oranı genel olarak ele alınmıştır. Ancak bu ameliyatın dizin lateral kompartman artriti üzerine olan olası etkileri için uzun dönem sonuçlar elimizde yoktur. Literatürde ALL'nin anatomisi, histolojisi, biyomekaniği, cerrahi tekniği ve radyolojisine ait birçok çalışma bulunurken bu alanda sınırlı sayıdaki kanıt düzeyi yüksek klinik çalışma mevcuttur.

Ueki ve ark., ALL rekonstrüksiyonu ile birlikte ÖÇB primer rekonstrüksiyonu ve revizyonu olan 15 hastanın biyomekanik analizinin yapıldığı bir laboratuvar çalışmasını 2019 yılında yayınlamışlardır. ${ }^{[30]}$ Bu çalışmaya dahil edilen 15 hasta; pivot sporlar, aşırı esneklik, operasyon öncesi yüksek dereceli pivot kaydırma ve revizyon olguları gibi tekrar yaralanma riski yüksek en az iki yıl takibi olan ÖÇB rekonstrüksiyonu olgularından seçilmiştir. Aynı risk grubuna sahip 15 sadece ÖÇB rekonstrüksiyonu yapılan olgu ile kontrol grubu oluşturulmuştur. Triaksiyel akselerometre kullandıkları ölçümlerde hem primer hem de revizyon olgularında pivot kaydırma akselerasyonunun (hızı) kontrol grubuna göre anlamlı olarak azaldığı ve çalışma grubunun kontrol grubuna göre iç rotasyonun sınırlandığı görülmüştür. Ayrıca ALL rekonstrüksiyonunun dizin doğal biyomekaniğine ek bir olumsuz etkisinin olmadığını da göstermişlerdir. Çalışmalarında çıkarım olarak yüksek risk grubu olan olgularda ALL rekonstrüksiyonunun da işleme eklenmesini önermektedirler.

Uluslararası Bilimsel ÖÇB Çalışma İşbirliği Grubu (SANTI) ortalama dört yıl takibi olan 70 profesyonel sporcunun sonuçlarını 2019 yılında yayımlamıştı. ${ }^{[31]}$ Çalışma kriterleri olarak IKDC (International Knee Documentation Committee), Tegner ve Lysholm skorları ve pivot kaydırma dereceleri ameliyat öncesi ve sonrası değerlendirilmiştir. Ayrıca spora dönüş ve süresi ile karşı dizin yaralanma hızı da ele alınan çalışmada bütün kriterler göz önüne alındığında $A L L+$ ÖÇB rekonstrüksiyonu olan hasta sonuçları olumlu olarak yorumlanmıştır. Ayrıca bu çalışmanın sonuçları arasında 11 hastanın karşı dizinin de ÖÇB yaralanması olması ve kadın hastaların tekrar yaralanma riskinin yüksek olması da ALL rekonstrüksiyonu açısından endikasyonların genişlemesine neden olmuştur.

Feretti ve ark. Segond kırığı olan 12 hastayı retrospektif olarak incelemişlerdir. ${ }^{\left[{ }^{[2]}\right]}$ Ameliyat öncesi yüksek dereceli pivot kayması olan bu hastaların kırıkları fikse edilmiş ve anterolateral kapsüler plikasyon yapılmıştır. Ameliyat öncesi ve sonrası anterior translasyon, pivot kaydırma, Tegner, Lysholm ve IKDC skorları incelendiğinde istatistiksel olarak olumlu sonuçların elde edildiğini rapor etmişler ve eğer ÖÇB yaralanmasına Segond kırı̆̆ı eşlik ediyorsa kırı̆̆ın tamir edilmesini ve kapsüler plikasyon işleminin yapılmasını önermişlerdir.

SANTI Çalışma Grubu 502 yüksek riskli olgulardan oluşan prospektif karşılaştırmalı çalışmalarında ALL ile birlikte dörde katlanmış hamstring greft (HSG) rekonstrüksiyonunu kemik patellar tendon (KPT) ve dörde katlanmış HSG kullanılan ÖÇB rekonstrüksiyonu greft sağ kalımı açısından incelemişlerdir. ${ }^{[33]}$ Ortalama iki yıllık takiplerini sonucunda ALL + HGS rekonstrüksiyonu yapılan olguların greft tekrar yaralanmasının izole KPT rekonstrüksiyonu yapılan hastalardan 2,5 kat ve izole dört kat HSG olgularından 3,1 kat daha az olduğunu rapor etmişlerdir. İzole KPT ve HSG kullanılan hastaların ise greft sağ kalımı açısından farklılık bulunmamıştır. Çalışmanın bir başka sonucu ise yaralanma öncesi sportif seviyeye ulaşma açısından ALL + HSG rekonstrüksiyonu izole HSG ile rekonstrüksiyona göre daha başarılı bulunmuştur. Çalışma grubu yüksek riskli olgularda ALL rekonstrüksiyonunun işleme eklenmesinin greft sağ kalımı ve spora dönüş açısından başarııı olduğu sonucuna varmışlardır.

Imbert ve ark., 482 olguluk retrospektif serisinde ALL rekonstrüksiyonunun pivot kaydırma, ikincil osteoartritik değişikler ve meniskal yaralanmalar üzerine etkilerini incelemiştir. ${ }^{[34]}$ Ortalama yedi yıllık takiplerinin sonucunda ALL rekonstrüksiyonu sonrası 
pivot kaydırma testinin \%83 olguda tespit edilemediğini, \%95 olguda karşı tarafla kıyaslandığında ön arka diz laksisitesinin $5 \mathrm{~mm}$ altında kaldığını, \%94,6 olguda tekrar yaralanma olmadığını, \%93,7 olguda ameliyat sonrası ek bir meniskal işleme gereksinim olmadığını ve olguların \%17,5'inde ikincil artritik değişikliklerin radyolojik olarak saptandığını rapor etmişlerdir. Çalışmanın çıkarımı olarak ALL rekonstrüksiyonunun klinik sonuçları tatminkâr olmakla beraber osteoartrit gelişiminin mutlak önüne geçmediği özetlenebilir.

Son olarak ALL Çalışma grubu klinik çalışmaların sonucunu yüksek riskli hastalar olan 20 yaş altı, pivot sporlarla uğraşan ve dizinde hiperlaksitesi olan olgularda pivot kaydırma fenomenini azaltması, greft sağ kalımına olumlu etkisinin olması ve ek morbiditesinin olmaması şeklinde özetlemişlerdir. Ayrıca literatür birikiminin anatomik ALL rekonstrüksiyonu eğer diz nötral rotasyon ve ekstansiyonda tespit edilirse lateral kompartman basıncı üzerinde olumsuz etkisi olmadığı şeklinde bilgilendirmede bulunmuşlardır. ${ }^{[18]}$

\section{SONUÇ}

ALL'nin, üzerinde çalışılan kadavraların büyük çoğunluğunda bulunan dizin anterolateral bölgesinde yer alan farklı bir anatomik yapı olduğuna şüphe yoktur. Bu yapının histolojik özelliği eklem kapsülünden farklı ligament ile uyumludur. Son yayınlar doğrultusunda, Segond kırığının biyomekanik temeli ALL avulsiyon hasarı ile korelasyon göstermektedir. Bununla birlikte, pivot kaydırma fenomeni Segond kırığı varlığında ÖÇB hasarı olan hastalarda daha belirgindir.

ALL hakkındaki bilgimiz ağırlıklı olarak kadavra çaIışmalarına dayanmaktadır. Literatürde ALL'nin in vivo klinik önemi halen yeterli değildir. Cevaplanmamış bir soru da ALL yaralanmasının doğal seyridir. ALL'nin eklem dışı bir yapı olduğundan potansiyel bir iyileşme kapasitesine sahiptir. Bu nedenle, akut fazda görüntüleme yöntemleri ile teşhis edilmesine rağmen, hangi hastaların ALL rekonstrüksiyonu için en uygun aday olduğu hala klinik bir sorudur.

Ayrıca, pivot kaymasının zaman içindeki değişikliklerini bilmiyoruz. Yaygın bir inanç, kronik hastaların büyük pivot kaydırma testine sahip olmalarıdır, ancak bu klinik bulgu iyi tasarlanmış klinik çalışmalarla kanıtlanmamıştır. ÖÇB rekonstrüksiyon prosedürlerinden sonraki devam eden instabilite modellerini anlamak için daha fazla bilimsel araştırmaya ihtiyaç olduğu açıktır. İleri anatomik, biyomekanik ve radyolojik çalışmalar ile altta yatan patolojiler daha da açıklığa kavuşturulacaktır.

\section{KAYNAKLAR}

1. Kosy DJ, Soni A, Venkatesh R, Mandalia Cl. The anterolateral ligament of the knee: unwrapping the enigma. Anatomical study and comparison to previous reports. J OrthopTraumatol 2016;17(4):303-8. Crossref

2. Trojani $C$, Beaufils $P$, Burdin $G$, Bussière $C$, Chassaing $V$, Djian P, Frédéric Dubrana, Ehkirch FP, Franceschi JP, Hulet $C$, Jouve F, Potel JF, Sbihi A, Neyret P, Colombet P. Revision ACL reconstruction: influence of a lateral tenodesis. Knee Surg Sports Traumatol Arthrosc 2012;20(8):1565-70. Crossref

3. Tanaka M, Vyas D, Moloney G, Bedi A, Pearle AD, Musahl V. What does it take to have a high-grade pivot shift? Knee Surg Sports Traumatol Arthrosc 2012;20(4):737-42. Crossref

4. Champat P, Guier C, Sonnery-Cottet B, Fayard JM, Thaunat $M$. The evolution of $A C L$ reconstruction over the last fifty years. Int Orthop 2013;37(2):181-6. Crossref

5. Monaco E, Ferretti A, Labianca I, Maestri B, Speranza A, Kelly MJ, D'Arrigo C, Ferretti A. Navigated knee kinematics after tear of the ACL and its secondary restraints: preliminary results. Orthopedics 2010;33(10):87-93. Crossref

6. Claes S, Vereecke E, Maes M, Victor J, Verdonk P, Bellemans J. Anatomy of the anterolateral ligament of the knee. J Anat 2013;223(4):321-8. Crossref

7. Segond P. Recherches cliniques et experimentales sur les epanchements sanguins du genou par entorse. Paris: Progrés Médical 1879. pp.1-85.

8. Campos JC, Chung CB, Lektrakul N, Pedowitz R, Trudell D, Yu $\mathrm{J}$, Resnick D. Pathogenesis of the Segond fracture: anatomic and MR imaging evidence of an iliotibial tract or anterior oblique band avulsion. Radiology 2001;219(2):381-6. Crossref

9. Hughston JC, Andrews JR, Cross MJ, Moschi A. Classification of knee ligament instabilities. Part 2. The lateral compartment. J Bone Joint Surg Am 1976;58(2):173-9. Crossref

10. Daggett $M$, Ockuly AC, Cullen M, Busch K, Lutz C, Imbert $P$, Sonnery-Cottet B. Femoral origin of the anterolateral ligament: an anatomical analysis. Arthroscopy 2016;32(5):835-41. Crossref

11. Terry GC, LaPrade RF. The posterolateral aspect of the knee. Anatomy and surgical approach. Am J Sports Med 1996;24(6):732-9. Crossref

12. Vieria EL, Vieria EA, da Silva RT, Berlfein PA, Abdalla RJ, Cohen $\mathrm{M}$. An anatomic study of the iliotibial tract. Arthroscopy 2007;23(3):269-74. Crossref

13. Vincent JP, Magnussen RA, Gezmez F, Uguen A, Jacobi M, Weppe F, Saati MFA, Lustig S, Demey G, Servien E, Neyret P. The anterolateral ligament of the human knee: an anatomic and histologic study. Knee Surg Sports Traumatol Arthrosc 2012;20(1):147-52. Crossref

14. Maeseneer M, Boulet C, Willekens I, Lenchik L, Mey JD, Cattrysse E, Shahabpour M. Segond fracture: involvement of the iliotibial band, anterolateral ligament, and anterior arm of the biceps femoris in knee trauma. Skeletal Radiol 2015;44(3):413-21. Crossref

15. Galway RD, Beaupre A, Maclntosh DL. Pivot shift: a clinical sign of symptomatic anterior cruciate insufficiency. J Bone Joint Surg (Br) 1972;54-B:763-4.

16. Kittl C, El-Daou H, Athwal KK, Gupte CM, Weiler A, Williams $A, A m i s$ AA. The role of the anterolateral structures and the $A C L$ in controlling laxity of the intact and $A C L$-deficient knee. Am J Sports Med 2016;44(4):NP15-8. Crossref

17. Daggett M, Busch K, Sonnery-Cottet B. Surgical dissection of the anterolateral ligament. Arthrosc Tech 2016;5(1):e185-8. Crossref 
18. Sonnery-Cottet B, Daggett M, Fayard JM, Ferretti A, Helito $\mathrm{CP}$, Lind $\mathrm{M}$, Monaco $\mathrm{E}$, de Pádua VBC, Thaunat $\mathrm{M}$, Wilson A, Zaffagnini S, Zijl J, Claes S. Anterolateral ligament expert group consensus paper on the management of internal rotation and instability of the anterior cruciate ligamentdeficient knee. J Orthop Traumatol 2017;18(2):91-106. Crossref

19. Helito CP, Demange MK, Bonadio MB, Tirico LEP, Gobbi RG, Pecora JR, Camanho GL. Radiographic landmarks for locating the femoral origin and tibial insertion of the knee anterolateral ligament. Am J Sports Med 2014;42(10):235662. Crossref

20. Kennedy MI, Claes S, Fuso FAF, Williams BT, Goldsmith MT, Turnbull TL, Wijdicks CA, LaPrade RF. The anterolateral ligament: An anatomic, radiographic, and biomechanical analysis. Am J Sports Med 2015;43(7):1606-15. Crossref

21. Rezansoff AJ, Caterine S, Spencer I, Tran MN, Litchfield RB, Getgood AM. Radiographic landmarks for surgical reconstruction of the anterolateral ligament of the knee. Knee Surg Sports Traumatol Arthrosc 2014;23(11):3196-201. Crossref

22. Heckmann N, Sivasundaram L, Villacis D, Kleiner M, Yi A, White E, Rick Hatch GFR 3rd. Radiographic landmarks for identifying the anterolateral ligament of the knee. Arthroscopy 2016;32(5):844-8. Crossref

23. Parsons EM, Gee AO, Spiekerman C, Cavanagh PR. The biomechanical function of the anterolateral ligament of the knee. Am J Sports Med 2015;43(3):669-74. Crossref

24. Roessler PP, Schuttler KF, Heyse TJ, Wirtz DC, Efe T. The anterolateral ligament (ALL) and its role in rotational extra-articular stability of the knee joint: a review of anatomy and surgical concepts. Arch Orthop Trauma Surg 2016;136(3):305-13. Crossref

25. Pomajzl R, Maerz T, Shams C, Guettler J, Bicos J. A review of the anterolateral ligament of the knee: Current knowledge regarding its incidence, anatomy, biomechanics, and surgical dissection. Arthroscopy 2015;31(3):583-91. Crossref

26. Oshima T, Nakase J, Numata $H$, Takata $Y$, Tsuchiya $H$. Ultrasonography imaging of the anterolateral ligament using real-time virtual sonography. Knee 2016;23(2):198-202. Crossref

27. Klontaz ME, Maris TG, Zibis AH, Karantanas AH. Normal magnetic resonance imaging anatomy of the anterolateral knee ligament with a T2/T1-weighted 3-dimensional sequence: a feasibility study. Can Assoc Radiol J 2016;67(1):52-9. Crossref
28. Helito CP, Helito PVP, Costa HP, Bordalo-Rodrigues M, Pecora JR, Camanho GL, Demange MK. MRI evaluation of the anterolateral ligament of the knee: assessment in routine 1.5-T scans. Skeletal Radiol 2014;43(10):1421-7. Crossref

29. Taneja AK, Miranda FC, Braga CA, Gill CM, Hartmann LG, Santos DC, Rosemberg LA. MRI features of the anterolateral ligament of the knee. Skeletal Radiol 2015;44(3):403-10. Crossref

30. Ueki $\mathrm{H}$, Katagiri $\mathrm{H}$, Otabe K, Nakagawa $\mathrm{Y}$, Ohara T, Shioda M, Kohno Y, Hoshino T, Sekiya I, Koga H. Contribution of Additional Anterolateral Structure Augmentation to Controlling Pivot Shift in Anterior Cruciate Ligament Reconstruction. Am J Sports Med 2019;47(9):2093-101. Crossref

31. Rosenstiel N, Praz C, Ouanezar $H$, Saithna A, Fournier $Y$, Hager JP, Thaunat M, Sonnery-Cottet B. Combined Anterior Cruciate and Anterolateral Ligament Reconstruction in the Professional Athlete: Clinical Outcomes from the Scientific Anterior Cruciate Ligament Network International Study Group in a Series of 70 Patients with a Minimum Follow-Up of 2 Years. Arthroscopy 2019;35(3):885-92. Crossref

32. Ferretti A, Monaco E, Wolf MR, Guzzini M, Carli A, Mazza D. Surgical Treatment of Segond Fractures in Acute Anterior Cruciate Ligament Reconstruction. Orthop J Sports Med 2017;5(10):2325967117729997. Crossref

33. Sonnery-Cottet B, Saithna A, Cavalier M, Kajetanek C, Temponi EF, Daggett M, Helito CP, Thaunat M. Anterolateral Ligament Reconstruction is Associated with Significantly Reduced ACL Graft Rupture Rates at a Minimum Followup of 2 Years: A Prospective Comparative Study of 502 Patients from the SANTI Study Group. Am J Sports Med 2017;45(7):1547-57. Crossref

34. Imbert $\mathrm{P}$, Lustig $\mathrm{S}$, Steltzlen $\mathrm{C}$, Batailler C, Colombet $\mathrm{P}$, Dalmay F, Bertiaux S, D'ingrado $P$, Ehkirch FP, Louis ML, Pailhé R, Panisset JC, Schlaterrer B, Sonnery-Cottet B, Sigwalt L, Saragaglia D, Lutz C; French Arthroscopy Society. Midterm results of combined intra- and extra-articular ACL reconstruction compared to historical $A C L$ reconstruction data. Multicenter study of the French Arthroscopy Society. Orthop Traumatol Surg Res 2017;103(8):S215-21. Crossref 